\title{
From Generation to Generation: Survival and Maintenance of Canada's Aboriginal Languages, within Families, Communities and Cities
}

Mary Jane Norris

The survival and maintenance of Aboriginal languages in Canada depend on their transmission from generation to generation. Children are the future speakers of a language. This paper demonstrates that the family and the community together play critical roles in the transmission of language from parent to child. On their own, neither family capacity nor community support is sufficient to ensure the adequate transmission of an Aboriginal language as a population's mother tongue from one generation to the next. Intergenerational transmission is maximized in Aboriginal communities among families where both parents have an Aboriginal mother tong ue. Transmission can be best realized with the support of the community in those families with either both parents or the lone parent having an Aboriginal mother tongue. Outside of Aboriginal communities, particularly within large cities, transmission and continuity is significantly reduced even under ideal family conditions of linguistically endogamous parents. For exogamous families, it appears that community effect, while positive, is nevertheless limited in offsetting their low rate of mother tongue transmission. Trends indicate continuing declines in intergenerational transmission accompanied by a decreasing and ageing Aboriginal mother tongue population and a growing likelihood that Aboriginal languages will be learned increasingly as second languages.

\section{Introduction}

Language transmission from one generation to another is the major factor in Aboriginal language survival and maintenance. Like other minority languages, the continual exposure to the more dominant languages, with the necessity to use them in everyday life is a powerful catalyst for the decline of Aboriginal languages. Many of Canada's Aboriginal languages are endangered and have already suffered great losses due to the forces of modernization, discouragement in residential schools, the influence of dominant

This article was first published in J. Blythe \& R. McKenna Brown (Eds.), (2003). Maintaining the Links: Language Identity and the Land. Proceedings of the 7th FEL Conference (reprinted by permission). The French translation of the abstract appears at the end of the article. 
languages, and possibly the fact that many Aboriginal languages are predominantly oral.

For Aboriginal languages, the language outcomes of children are significant for their very survival. Intergenerational transmission is essential for both the maintenance of still viable languages and for revitalization of endangered languages. Increasing the number of second-language speakers can contribute to the process of revitalization, but it is still not equivalent to learning a language as a mother tongue, in order to increase the number of first-language speakers and to restore transmission of that language from one generation to the next. Unlike other heritage language groups in Canada, Aboriginal languages cannot rely on immigration flows for maintaining the population of speakers.

This paper focuses on the intergenerational transmission of Aboriginal languages from parent to child, within families, communities and cities. Based on the 1996 Census family file, as well as other census data on language from 1981 to 2001, this study is an extension of previous work on Aboriginal languages that separately examined intergenerational transmission within families (Norris and MacCon, forthcoming) ${ }^{1}$ and the viability of languages within Aboriginal communities and cities (Norris and Jantzen, forthcoming). Patterns and extent of transmission are analysed for the first time by the family's place of residence, within Aboriginal communities and cities, in order to understand the interplay between family and community in passing the language from parent to child. As in the previous analysis, transmission from parent to child, explored within families where at least one parent has an Aboriginal mother tongue, ${ }^{2}$ can be assessed in three ways using the census language variables: (1) language can be transmitted to the child as a mother tongue, (2) the child can use the language in the family as the predominant home language, ${ }^{3}$ and (3) the child

can have knowledge of, ${ }^{4}$ or ability to speak the language well enough to conduct a conversation. With respect to knowledge, the child could learn his parent's Aboriginal language either as a mother tongue or as a second language, a relevant consideration as there is ongoing and concerted effort to provide instruction to children in their indigenous languages.

Transmission of Aboriginal languages from parent to child is examined within the child's family in relation to family structure, linguistic intermarriage and parent gender, yielding the following five family "types": husbandwife endogamous (both husband and wife have an Aboriginal mother tongue), exogamous by husband marrying wife with non-Aboriginal mother tongue, exogamous by wife marrying husband with non-Aboriginal mother tongue, male lone parent and female lone parent. Patterns and rates of transmission are examined for each of these types by the family place of residence, within Aboriginal communities ${ }^{5}$ and cities using four mutually exclusive and exhaustive geographies: reserves, rural areas, non-Census Metropolitan areas 
(CMAs) urban areas (comprising small urban areas and urban Census Agglomerations (CAs) with an urban core population of at least 10,000 but less than 100,000), and urban CMAs-large cities with an urban core population of at least 100,000.

Before proceeding to the findings, the paper provides a brief background on Aboriginal languages, a discussion on language continuity and demographic trends, and summaries of the two previous studies that this current study derives from. The study concludes with a brief discussion on the implications for future research directions and some policy and program considerations for Aboriginal languages in Canada.

\section{Background on Aboriginal Languages}

The variety in Aboriginal culture and identity is reflected in Canada's Aboriginal languages, which are many and diverse. Today, some 50 individual languages belong to 11 Aboriginal language families or isolates (languages that cannot be related to any of the major families)-10 First Nations and Inuktitut. Most language families consist of separate but related member languages (e.g. the Algonquian language family consists of individual languages such as Cree, Blackfoot, and Algonquin amongst others), as well as separate dialects. For discussions on size, diversity and viability of Canada's Aboriginal languages see Kinkade (1991) and Norris (1998).

In 1996 some 800,000 people reported an Aboriginal identity. Only $207,000(26 \%)$ reported an Aboriginal language as their mother tongue (or first language learned and still understood). Even fewer, $145,000(18 \%)$ people reported an Aboriginal language as that being spoken most often in the home, implying that learning an Aboriginal mother tongue does not guarantee continued use. However, some 233,000 Aboriginal respondents $(30 \%)(239,000$ total respondents) reported that they could speak and understand an Aboriginal language well enough to conduct a conversation. Clearly, then, while some people shift from an Aboriginal language to another home language, others may be either learning indigenous languages or beginning to use the language later in life, a phenomenon that appears to be especially pronounced for younger generations learning endangered languages and as well, in urban areas (Norris and Jantzen, 2003).

\section{Population Size, Language Continuity and $\mathrm{Age}^{6}$}

Several factors significant to the viability of Aboriginal languages have been identified in previous work: population size, age, second language acquisition, and community. The size of the language population has an impact in ensuring the survival of the language in the long-term. However, only three (Cree, Inuktitut and Ojibway) out of 50 Aboriginal languages have sufficient ly large populations. Use of the language at home is vital to an assessment of 
a language's viability and can be established using a continuity index. ${ }^{7}$ Many of the large population languages also have high continuity, while those with smaller populations under 1,000 (e.g., Nishga, Haida) may be endangered or faced with extinction by low continuity. However, some of the smaller languages (e.g., Attikamek, Dene) can still be considered viable if their continuity is high.

Age is also a factor in language continuity. The average age of those who have an Aboriginal mother tongue or speak the language at home is an indication of the extent to which the language has been transmitted to the younger generation. Viable languages like Attikamek, Inuktitut and Dene are characterized by relatively young mother tongue populations (average age 22-25) and corresponding high continuity. In contrast, endangered languages like Haida, Kutenai and Tlingit typically have older mother tongue populations (average age around 50 ) combined with very low continuity indexes.

Age and continuity factors do not tell the whole story however, since second language acquisition is prevalent among younger generations. For example, the Kutenai language family has one of the oldest mother tongue populations and lowest continuity indexes but the index of ability ${ }^{8}$ indicates that there are two people (usually younger) who speak the language to every one individual with a mother-tongue, suggesting that younger generations are more likely to learn Kutenai as a second language. Second language acquisition patterns are also more highly pronounced off-reserve, especially among youth in urban areas (Norris and Jantzen). It should be noted, though, that with respect to second-language acquisition, varying degrees of fluency could be represented among census respondents reporting knowledge of the language-that is, the ability to conduct a conversation in an Aboriginal language-suggesting some caution in considering the implications of second language acquisition for transmission and continuity.

\section{Trends Over the Past Twenty Years, 1981 to 2001}

Figures 1 and 2 illustrate the relationship between continuity and age over the last twenty years of census data in Canada. The strength of Aboriginal language continuity declined steadily between 1981 and 2001, indicating signs of steady erosion in home language use. For Aboriginal languages as a whole, average ages are getting higher-the average age of the mother tongue population rose by $51 / 2$ years to reach 33 in 2001 (Figure 1). Two main factors are responsible for this ageing trend: (1) declining fertility rates, although still high, are translating into relatively fewer children; and (2) declining continuity means lower rates of mother tongue transmission from parent to child and hence fewer children learning the language as a mother tongue. As a consequence, the share of children in the population with an Aboriginal mother tongue has been decreasing such that children, aged 0 to 


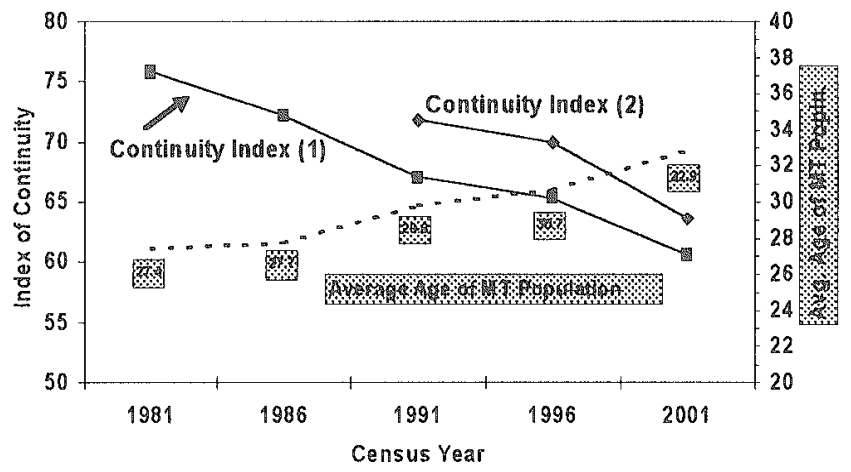

(1) Based on Single Responses to language (MT, HL) questions.

(2) Based on Single and Multiples Responses.

Figure 1: Aboriginal Languages: Index of Continuity and Average Age of Mother Tongue Population, Canada, 1981 to 2001

Source: 1981-2001 Censuses, author's calculations.

19 years, as a percentage of the mother tongue population declined from $41 \%$ in 1986 to $32 \%$, while the share of adults aged 55 and over increased from $12 \%$ to $17 \%$ (Figure 2 ).

The 2001 Census data suggest a continued erosion of Aboriginal languages. Although there appears to be relatively little change from 1996 in the population reporting knowledge of, or ability to speak, an Aboriginal language, at about 239,000, the population reporting an Aboriginal mother

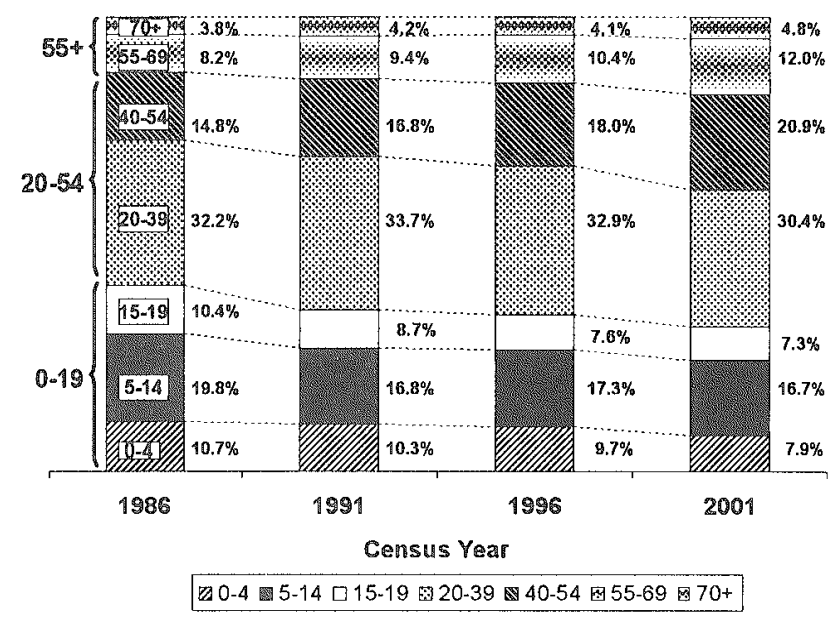

Figure 2: Population with Aboriginal Mother Tongue by Age Groups, 1986 to 2001

Source: 1986-2001 Censuses, author's calculations. 
tongue in Canada declined for the first time since 1981 from some 208,600 in 1996 to 203,900 in 2001. Such a decline attests to the impact of declining trends in continuity and consequently in transmission to younger generations-which no longer seems to be offset by still relatively high levels of Aboriginal fertility. Correspondingly, among the population reporting an Aboriginal identity, the proportion with an Aboriginal mother tongue dropped from some $26 \%$ in 1996 to just $20 \%$ in $2001,{ }^{9}$ while corresponding percentages for children under age 5 decreased from $20 \%$ to $15 \%$. Given UNESCO's (1996) caution that a language is endangered if it is not learned by at least $30 \%$ of the children in that community, it becomes apparent that the transmission from parent to child is a key concern for Aboriginal languages in Canada, in which, as this study shows, both family and community play a critical role.

\section{Survival and Maintenance within Communities and Cities ${ }^{10}$}

Aboriginal communities, including the First Nation reserves of registered Indians and the northern communities of the Inuit, clearly support the maintenance and transmission of Aboriginal languages, as evidenced by sizable mother tongue populations and high continuity. In 1996, 52\% of registered Indians living on reserves and $67 \%$ of Inuit (most of whom live in northern communities) reported an Aboriginal mother tongue, compared to only $18 \%$ of registered Indians off reserve, $6 \%$ of non-status Indians, and $7 \%$ of Métis.

But, not all Aboriginal people reside in such communities-in the 1996 Census some 37,000 persons, or close to one in five persons who reported an Aboriginal mother tongue were residing in major cities across Canada. Compared to the Aboriginal population overall, and especially with Aboriginal communities, the off-reserve Aboriginal population, particularly in "cities," does not fare well in its language use as indicated in Figure 3. For example, only $3 \%$ of Aboriginal people in cities reported an Aboriginal home language, compared to $18 \%$ overall and $41 \%$ for reserves. The study's findings on the low continuity and ageing of mother tongue populations in urban areas; the fact that Aboriginal languages are being spoken relatively little in the homes of urban residents, and that children in cities are much more likely to learn an Aboriginal language as a second language confirm the conclusion by Canada's Royal Commission on Aboriginal Peoples (RCAP) that many of the challenges confronting Aboriginal languages are exacerbated in an urban environment (RCAP (1996), Volume 3, p 614-617).

\section{Survival and Maintenance within Families}

Language Maintenance and Life Cycle

A cohort analysis of census data (1981-1996) shows that the maintenance of an Aboriginal mother tongue as a home language is related to the life cycle: 


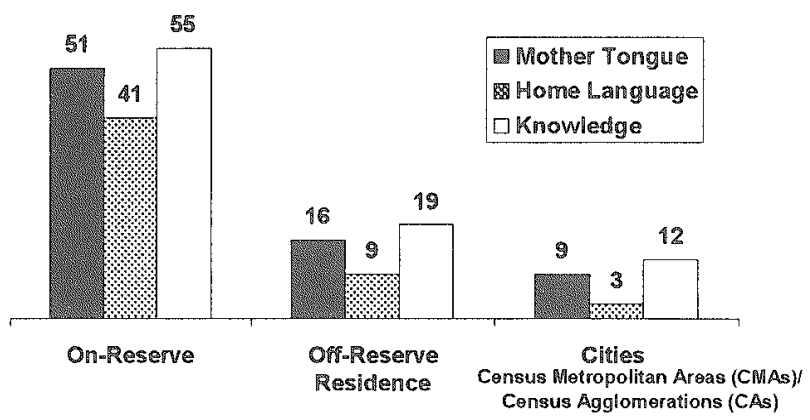

Figure 3: Percentage of Aboriginal Identity Population with Aboriginal Mother Tongue, Home Language or Knowledge by Place of Residence, Canada, 1996

Source: 1996 Census custom tabulations, from Norris and Jantzen, forthcoming.

language loss is most liable to occur during the family formation years as youth leave home, enter the labour force, marry, start families or move to a larger urban environment. The most pronounced decline-among women aged 20 to 24 in 1981 to 35 to 39 in 1996-is significant given that these are the very years during which women tend to bring up young children. Compared to men, women tend to have higher rates of migration from reserves to cities, and are consequently more likely to intermarry-especially relevant for endangered languages that have high rates of exogamy and urbanization (Norris, 1998).

\section{Exogamy, Language Continuity, Transmission}

A high degree of linguistic out-marriage (exogamy) is associated with diminished continuity of language. Consistent with Harrison (1997), Figure 4 illustrates the strong inverse linear association between language continuity (for all ages) and exogamy (\% of children in mixed marriages) for Aboriginal languages. Viable languages with extremely high language continuity $(80 \%+)$ such as Attikamek, Montagnais-Naskapi and Inutktitut and low exogamy rates $(<20 \%)$ are in the top left corner of the graph. In contrast, endangered languages such as Haida, Tlingit and Kutenai are in the opposite lower right hand corner with extremely low continuity levels of $20 \%$ or less and exogamy rates averaging some $90 \%$. The largest First Nation language, Cree, is in the upper left quadrant with continuity and exogamy rates of about $70 \%$ and $30 \%$ respectively.

\section{Transmission from Parent to Child: Mother Tongue, Home}

\section{Language, Second Language?"11}

Among the study population of the 58,000 children (aged 5 -14) who have a parent(s) with an Aboriginal mother tongue, overall 54,000, (over $90 \%$ ) of these children have the ability (knowledge) to conduct a conversation in the 


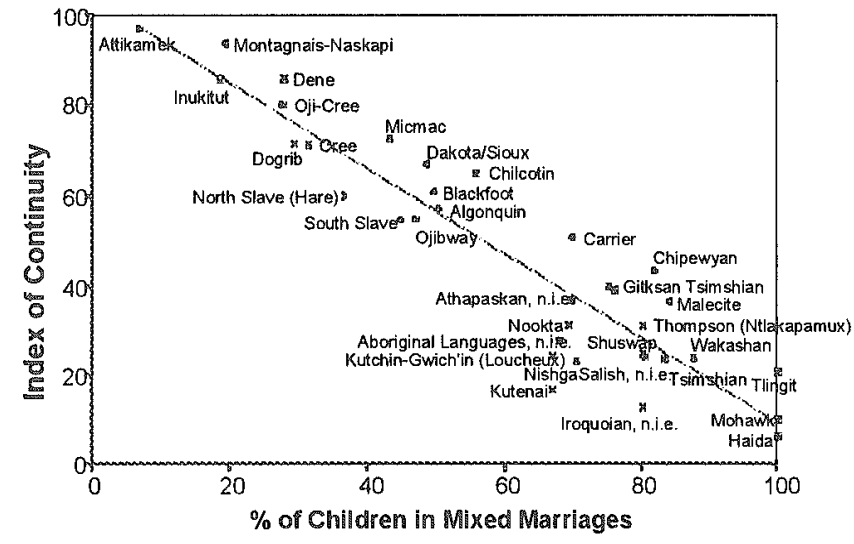

Figure 4: Aboriginal Language Continuity and Percentage of Children in Exogamous Marriages, by Aboriginal Language of Parent(s), Canada, 1996

Source: 1996 Census, from Norris and MacCon.

Aboriginal language of their parent; but only $27,000(47 \%)$ of children have their parent(s)' Aboriginal mother tongue; while only 22,000 (38\%) of children speak an Aboriginal language at home. The erosion of home language use occurring among younger generations is most pronounced for endangered languages which practically none of the children speak at home and which are more likely to be learned as a second language than as a mother tongue - trends that contribute to the ageing of their first-language speakers and that ultimately could push endangered languages closer to extinction.

\section{Patterns of Transmission by Family "Type"}

The transmission of an Aboriginal mother tongue from parent to child varies by family type in relation to the child learning it as a mother tongue or speaking it in the home, but less so in the case of the child's reported knowledge of the language. The majority $(78 \%)$ of the children in the study population are in husband-wife families, with $51 \%$ and $27 \%$ in endogamous and exogamous marriages respectively; and the remaining $22 \%$ living in lone-parent families, $(86 \% \text { predominantly headed by female lone parents. })^{12}$ Children fare best in their language outcomes within endogamous families, with two out of three children acquiring an Aboriginal mother tongue, followed by $40 \%$ in lone-parent families, generally being "worst off" within exogamous marriages at only $11 \%$. Home language use is minimal within exogamous families: less than $6 \%$ of children speak an Aboriginal language at home, a sharp contrast to the $58 \%$ of children in endogamous marriages, 
and still significantly lower than the $29 \%$ of children in female-headed loneparent families. The proportion of children with knowledge of an Aboriginal language varies considerably less by family type, ranging from a low of some $80 \%$ for exogamous to almost $100 \%$ for endogamous.

While children in lone-parent families do not fare as well in their language continuity as those in endogamous families, they do have better prospects than those within linguistically mixed marriages. There are also gender differences: for children who do have an Aboriginal mother tongue, mothers with an Aboriginal mother tongue either in exogamous marriages or as lone parents are less likely than their male counterparts to use their Aboriginal language "most often" in the home (a reflection in part of the greater propensity of women to live off reserve). This pattern is observed for viable languages; in the case of endangered ones continued home language use is practically non-existent among those children who do have an Aboriginal mother tongue. Also, the index of ability suggests that compared to children in endogamous families, those in exogamous families-especially those where it is the mother who has a non-Aboriginal mother tongue, are much more likely to learn the Aboriginal language as a second language instead of as a mother tongue. Indication of second language acquisition is even more pronounced in the case of endangered language, given the extremely small proportion of children with an Aboriginal mother tongue, often less than $5 \%$, relative to the proportion reporting knowledge of the language.

\section{Survival and Maintenance within Families by Communities and Cities}

The new analysis undertaken here provides further understanding of the interplay between family type and location, and of the impact of residence in an Aboriginal community in relation to language transmission. As this study demonstrates, not only do family types differ in their residential distributions, they also differ in how their place of residence, whether an Aboriginal community or a large city, affects their patterns and extent of language transmission from parent to child.

Residential Variations in Family "Types"

As expected, given differential rates of intermarriage, fertility and migration by both residence and gender, the residential distributions of family types vary. For example, higher proportions of children in endogamous $(70 \%)$ male lone parent (65\%) and exogamous husband (53\%) families, are located on reserves, compared to corresponding proportions for children in female lone parent $(46 \%)$ and exogamous wife $(39 \%)$ families, which are characterized by much higher shares of children in large cities, of some $40 \%$ each. 


\section{Transmission by Family Type and Residence}

About $84 \%$ of children with an Aboriginal mother tongue are concentrated in either endogamous or lone-parent female families located on reserve $(51 \%$ and $10 \%$ respectively) or in rural areas (19\% and $4 \%$ respectively). Similarly, children using an Aboriginal language at home are slightly more concentrated at $87 \%$, whereas children with knowledge of an Aboriginal language are more dispersed at $62 \%$, closer in distribution and share $(59 \%)$ to the study population of children overall. These comparisons suggest that the propensity of children to learn an Aboriginal mother tongue or to use it as a home language varies by family and residence, but less so for knowledge.

\section{Mother Tongue of Children by Family Residence}

Residence in an Aboriginal community varies in its impact on the child's mother tongue by family type. The highest proportions of children with an Aboriginal mother tongue are found among children of endogamous parents residing either on reserve $(68 \%)$ or in rural areas $(77 \%)$. In contrast, transmission of a mother tongue within endogamous families drops significantly in large cities to just $41 \%$ of children. Similar effects are observed for lone parent families-in the case of females-corresponding proportions of children are $53 \%$ on reserves and $13 \%$ in large cities (Figure 5).

For exogamous families, it appears that the effect of community, while positive, is nevertheless limited in offsetting the low rate of mother tongue transmission. Among children of exogamous couples in which the husband has a non-Aboriginal mother tongue, a lower proportion of those residing in large cities, $(8 \%)$, have an Aboriginal mother tongue, compared to those living on reserve $(18 \%$ )-although within Aboriginal communities this rate is relatively low, especially in comparison with male lone parent families

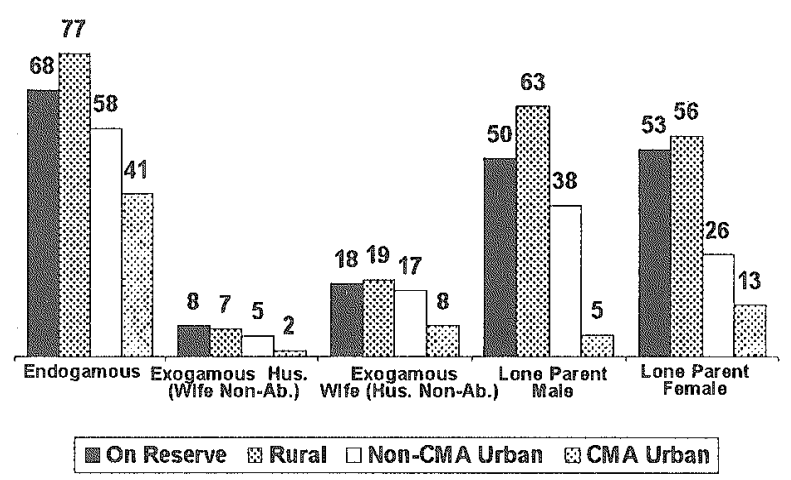

Figure 5: Percentage of Children with Aboriginal Mother Tongue, by Family Type and Residence, Canada, 1996

Source: 1996 Census, custom tabulations, author's calculations. 
where transmission rates on reserves are several times those in large cities. The community factor appears to be more salient for endogamous or loneparent families than for exogamous families (although communities where exogamous parenting is occurring may also be undergoing declines in language transmission). Nevertheless the findings suggest that the community best serves as a catalyst in the transmission from parent to child in those families where either both parents or the lone parent have an Aboriginal mother tongue, and are less likely to have to "compete" with the presence of a non-Aboriginal language in the household.

\section{Home language Use in Family and Community}

The indicator of home language use reflects the actual ongoing language use within the child's family type and residence at the time of enumeration, unlike that of mother tongue, which may not necessarily have been acquired within the child's current family and residence. ${ }^{13}$ Nevertheless, the patterns of children's home language use by family type and residence are similar to those observed with mother tongue transmission: the proportions of children speaking an Aboriginal language in the home are highest within endogamous families that reside in Aboriginal communities, either on reserves, at $58 \%$, or in rural areas at $68 \% .{ }^{14}$ When controlling for their place of residence, home language use is more similar between male and female lone parent families, such that on reserve about $40 \%$ of children of either a male or female lone parent speak an Aboriginal language at home. In large cities, home language use drops considerably to just $28 \%$ of children in endogamous and $3-5 \%$ in lone-parent families. Regardless of family residence, home language use fares worst in exogamous marriages (reserves having the highest proportion of home speakers at $9 \%$ ) especially in large cities where none of the children are using their mother tongue as the main home language. Consistent with these patterns, the index of continuity confirms that children of endogamous and lone parents are more likely to continue using their Aboriginal mother tongue at home in Aboriginal communities; for city children in exogamous families continuity is nil (Figure 6). For example, on reserves, for every 100 children with an Aboriginal mother tongue, within endogamous families there are 85 children that use an Aboriginal language as the main language at home, compared to 48 children within exogamous families.

\section{Knowledge of, or Ability to Speak, the Language}

The vast majority of children in this study have the knowledge or ability to speak an Aboriginal language, regardless of family type or residence. The index of ability shows that children in exogamous families or large cities are much more likely than those in endogamous or community lone-parent families to learn an Aboriginal language as a second language, since only 


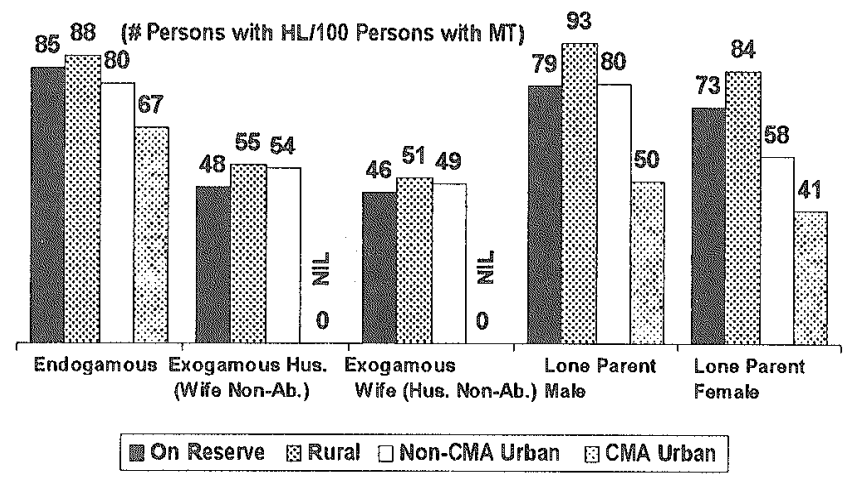

Figure 6: Aboriginal Language Index of Continuity, Canada, 1996 Source: 1996 Census, custom tabulations, author's calculations.

relatively small shares have learned an Aboriginal language as a mother tongue (Figure 7). For example, on reserves, for every 100 children with an Aboriginal mother tongue, within endogamous families there are 140 with the knowledge or ability to conduct a conversation in an Aboriginal language indicating that the majority of them learnt the language as a mother tongue; in contrast, within exogamous husband families the corresponding index of close to 1300 indicates that practically all transmission is second language acquisition.

("Persons with KN/100 Persons with MT)

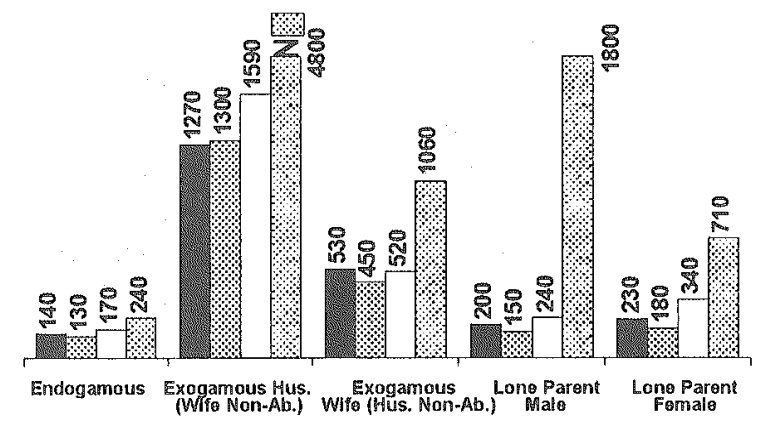

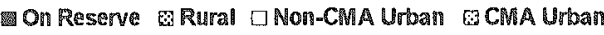

Figure 7: Aboriginal Language Index of Ability, Canada, 1996

Source: 1996 Census, custom tabulations, author's calculations. 


\section{Conclusion and Implications}

This study demonstrates that for Aboriginal languages both community and family are significant factors in the transmission from parent to child, affecting whether the child learns the Aboriginal language as a mother tongue or as a second language, or speaks it at home. The analysis suggests that families where the language has a strong presence in the home, where either both parents or the lone parent has an Aboriginal mother tongue, and that are located in Aboriginal communities provide the best conditions for a child to learn an Aboriginal language as a mother tongue and to speak it in the home.

Yet many Aboriginal children do not live in such ideal learning conditions, let alone have a parent(s) with an Aboriginal mother tongue, as evidenced by the continuing declines in continuity, with children comprising a shrinking share of the population with an Aboriginal mother tongue and increasingly more likely to learn an Aboriginal language as a second language, especially for endangered languages and in urban areas.

The findings of this study suggest a number of directions for future research. Given the increasing prevalence of second language acquisition it would be worthwhile to analyse patterns of language transmission in those families where parent(s) have learned an Aboriginal language not as a mother tongue but as a second language in order to better assess the prospects for long term transmission of Aboriginal languages. Patterns of home language use is another area of research that can be better studied with the introduction in the 2001 Census of the question on languages spoken "regularly" at home in addition to "most frequently." This additional element provides new and relevant insight into the use of Aboriginal languages within the home. Where Aboriginal languages are either endangered or spoken in urban areas, preliminary analysis suggests that although they tend not to be the ones spoken "most often" in the home, it appears that they are being used on a "regular basis," thereby contributing to some extent to the transmission process (Norris and Jantzen).

This study has implications for policy and programs affecting Aboriginal languages in a number of areas, such as revitalization, maintenance, immersion programs, second language learning, and general education and awareness about Aboriginal languages and cultures. The findings lend support to the importance of community and family in the maintenance of viable languages, and for the revitalization of endangered languages; and reinforce the role of community support and parent/family involvement, in addition to curriculum development and government support as components critical to the successful development of learning programs (Stiles, D.B. 1997).

Notes

${ }^{1}$ This study was based on two earlier pieces of work: Harrison, 1997 and Norris, 1998. 
${ }^{2}$ Mother tongue is defined as the first language learned at home in childhood and still understood by the individual at the time of the census.

${ }^{3}$ Home language is defined as language spoken most often at home by the individual at the time of the census. In the 2001 Census a new part on languages spoken on a regular basis at home was added (Statistics Canada, 2002). Here the analysis is restricted to language spoken most often.

${ }^{4}$ Knowledge of (non-official) languages refers to languages other than English or French in which the respondent can conduct a conversation. In the 2001 Census Guide respondents were instructed to report only those languages in which the person can carry on a conversation of some length on various topics (Statistics Canada, 2002).

${ }^{5}$ In the Census, while most Inuit communities are classified as rural areas, some Northern communities, comprised of mainly Inuit populations, such as Iqualuit and Rankin Inlet, are classified as "urban." Similarly while most First Nation (North American Indian) communities, mainly reserves, are rural some are classified as urban - though for this analysis urban and rural reserves are combined into one category.

${ }^{6}$ This section is derived from Norris, 1998.

${ }^{7}$ Index of Continuity (HL/MT) measures language continuity, or vitality, by comparing the number of those who speak a given language at home to the number of those who learned that language as their mother tongue. A ratio less than 100 indicates some decline in the strength of the language (i.e., for every 100 people with an Aboriginal mother tongue, there are fewer than 100 in the overall population who use it at home). The lower the score, the greater the decline or erosion.

${ }^{8}$ Index of Ability (KN/MT) compares the number of people who report being able to speak the language with the number who have that Aboriginal language as a mother tongue. If for every 100 people with a specific Aboriginal mother tongue, more than 100 persons in the overall population are able to speak that language, then some learned it as a second language either in school or later in life. This may suggest some degree of language revival.

${ }^{9}$ Caution is required in intercensal comparisons based on Aboriginal populations owing to ethnic mobility (Guimond, 1999).

${ }^{10}$ This section is derived from Norris and Jantzen, forthcoming. For sake of simplicity, the term "cities" is used interchangeably with the Statistics Canada definition of Census Metropolitan Area (CMA) and Census Agglomeration (CA).

${ }^{11}$ This section is derived from Norris and MacCon, forthcoming.

${ }^{12}$ The fact that there are more female than male lone parents with an Aboriginal mother tongue is consistent with the ratios in the general Aboriginal population. In 1996, 18\% of Aboriginal women in Canada (aged 15t) were heading families on their own compared to only $3 \%$ of Aboriginal men (Tait 2000, p. 253-54).

${ }^{13}$ Some caution must be used in interpreting the effect of residence and marriage type on the child's mother tongue. For example, after the child learned an Aboriginal mother tongue, the family could have moved from the reserve to the city or could have undergone dissolution from husband-wife to lone parent.

${ }^{14}$ The locations of Inuit communities in rural and small urban areas, which have higher rates of mother tongue and home language transmission than First Nations on reserves, underlie the overall high shares in these areas of children with an Aboriginal mother tongue or home language, corresponding to higher continuity and lower ability indexes (acquisition as second language is less likely for Inuit). 


\section{Acknowledgements}

The views expressed in this paper are those of the author and do not necessarily represent the views of Indian and Northern Affairs Canada (INAC). The author acknowledges with thanks technical support provided by Lucette Dell'Oso of the Strategic Research and Analysis Directorate (SRAD) and Gerry Ouellette of Statistics Canada, and editorial advice provided by Jordana Heaton of SRAD.

\section{The Author}

Mary Jane Norris is a Senior Research Manager with the Strategic Research and Analysis Directorate of the Department of Indian and Northern Affairs Canada. Prior to her current position, she focused on Aboriginal research in the Demography Division of Statistics Canada. She has specialized in Aboriginal demography over the past twenty years and has published in the areas of Aboriginal languages, population projections and migration. She is of Aboriginal ancestry, with family roots in the Algonquins of Pikw kanag n (Golden Lake), in the Ottawa Valley. Her most recent publications include: A chapter on the patterns and implications of Registered Indian mobility and migration in Population Mobility and Indigenous Peoples in Australasia and North America, edited by John Taylor and Martin Bell, Routledge Press, London, 2003; chapters on Aboriginal languages, migration, and population projections in Aboriginal Conditions: The Research Foundations of Public Policy, edited by Jerry White, Paul Maxim and Dan Beavon, Vancouver: UBC Press, 2003; chapters on the urban dimensions of Aboriginal languages and migration in Not Strangers in These Parts: Urban Aboriginal Peoples, edited by David Newhouse and Evelyn Peters, Policy Research Initiative, Ottawa, Government of Canada, 2003.

Strategic Research and Analysis Directorate, Indian and Northern Affairs Canada

10 Wellington St., 5- 18

Gatineau, Quebec, Canada, K1A 0H4

[norrism@inac.gc.ca]

La survie et le maintien des langues autochtones au Canada dépend de leur transmission d'une génération à l'autre. Les enfants représentent l'avenir d'une langue. Cet article explique les rôles critiques que jouent la famille et la communauté dans la transmission de la langue du parent à l'enfant. Pris seul, ni les capacités de la famille, ni l'appui communautaire ne suffisent à assurer la transmission adéquate d'une langue autochtone comme langue maternelle d'une génération à l'autre. Dans les communautés autochtones, la transmission intergénérationnelle connaît son efficacité maximale au sein des familles où les deux parents (ou le parent célibataire) ont une langue autochtone comme langue maternelle et où il existe un appui communautaire. À l'extérieur des communautés autochtones, surtout dans les grandes villes, la transmission et la continuité sont réduites de façon significative, même quand les deux parents sont de langue maternelle autochtone. Chez les familles exogames, l'influence de la communauté, quoique positive, ne semble pas suffire pour compenser le faible taux de transmission de la langue maternelle. Les tendances indiquent que les déclins dans la transmission intergénérationnelle se poursuivront, accompagnés d'un vieillissement et d'un rétrécissement de la population ayant comme langue maternelle une langue autochtone, le tout augmentant la probabilité que les langues autochtones s'apprendront de plus en plus comme langues secondes. 


\section{References}

Guimond, E. (1999). Ethnic Mobility and the Demographic Growth of Canada's Aboriginal Population from 1986-1996. In Demographic Situation of Canada, 1998-1999, Statistics Canada, Ottawa.

Harrison, B.R. (1997). Languages integration: Results of an intergenerational analysis. Statistical Journal of the United Nations ECE 14: 289-303.

Kinkade, M.D. (1991). The Decline of Native Languages in Canada. In Endangered languages, edited by Robert $H$. Robins and Eugenius M. Uhlenbeck. Published with the Authority of the Permanent International Committee of Linguists (CIPL), Berg.

Norris, M.J. (1998). Canada's Aboriginal Languages. Canadian Social Trends 51 (Winter), Statistics Canada, Cat. No. 11-008.

Norris, M.J. and L. Jantzen (forthcoming). Aboriginal Languages in Canada's Urban Areas: Characteristics, Considerations and Implications, in Urban Aboriginal Research, David Newhouse and Evelyn Peters (eds.), Government of Canada, Ottawa, 2003.

Norris, M.J. and K. MacCon (forthcoming). Aboriginal Language Transmission and Maintenance in Families: Results of An Intergenerational and Gender-Based Analysis for Canada, 1996, in Aboriginal Conditions: The Research Foundations of Public Policy. Jerry White, Paul Maxim and Dan Beavon, (eds), Vancouver, UBC Press, 2003.

Report of the Royal Commission on Aboriginal Peoples. (1996). Volume 3, Gathering Strength and Volume 4, Perspectives and Realities, Minister of Supply and Services Canada

Statistics Canada (2002). The 2001 Census Dictionary, Cat. No. 92-378-XIE.

Stiles, D.B. (1997). Four Successful Indigenous Language Programs. In J. Reyhner Teaching Indigenous Languages (pp. 248-262) Flagstaff, AZ, Northern Arizona University, Center for Excellence in Education.

Tait, H. (2000). Aboriginal Women, in Women in Canada. Statistics Canada, Cat. No. 89-503, XP3, pages 253-254.

UNESCO (1996). Atlas of the World's Languages in Danger of Disappearing, edited by Stephen A. Wurm, Paris, Canberra: Unesco Publishing and Pacific Linguistics. 